\title{
Microbial Growth on Dust-Loaded Filtering Materials Used for the Protection of Respiratory Tract as a Factor Affecting Filtration Efficiency
}

\author{
Katarzyna Majchrzycka ${ }^{1}$, Małgorzata Okrasa ${ }^{1, *(\mathbb{D})}$, Anita Jachowicz ${ }^{2}$, Justyna Szulc ${ }^{2}$ and \\ Beata Gutarowska ${ }^{2}$ \\ 1 Department of Personal Protective Equipment, Central Institute for Labour Protection-National Research \\ Institute, Wierzbowa 48, Łódź 90-133, Poland; kamaj@ciop.lodz.pl \\ 2 Faculty Biotechnology and Food Science, Institute of Fermentation Technology and Microbiology, \\ Lodz University of Technology, Wólczańska 171/173, Łódź 90-924, Poland; 801208@edu.p.lodz.pl (A.J.); \\ justyna.szulc@p.lodz.pl (J.S.); beata.gutarowska@p.lodz.pl (B.G.) \\ * Correspondence: maokr@ciop.lodz.pl; Tel.: +48-42-648-0223
}

Received: 3 August 2018; Accepted: 29 August 2018; Published: 1 September 2018

\begin{abstract}
This work aims at understanding the effects of various dust-loading conditions and the type of nonwovens used in the construction of FFRs on the safe use of those protective devices in situations of exposure to biological agents. The survival of microorganisms (Escherichia coli, Candida albicans, and Aspergillus niger) in dust-loaded polypropylene nonwovens (melt-blown, spun-bonded, and needle-punched) was experimentally determined using microbiological quantitative method (AATCC TM 100-2004). Scanning electron microscope was used to assess biofilm formation on dust-loaded filtering nonwovens. The impact of the growth of microorganisms on filtration efficiency of nonwovens was analysed based on the measurements of penetration of sodium chloride particles (size range 7-270 nm). Results showed that tested microorganisms were able to survive on dust-loaded polypropylene filtering nonwovens. The survival rate of microorganisms and penetration of nanoparticles and submicron particles depended on the type of microorganism, as well as the type and the amount of dust, which indicates that both of those factors should be considered for FFR use recommendations.
\end{abstract}

Keywords: microorganisms; respiratory protective equipment; organic/inorganic dust; risk assessment; workplaces

\section{Introduction}

Harmful biological agents in the work environment can have infectious, toxic, and/or allergenic effects on the human body. They pose a high risk in a number of workplaces, including those in health care, laboratory, and veterinary facilities; agriculture, forestry, food, textile, mining, and wood industry; waste collection, sorting, and processing companies; art conservation and many others [1]. Most commonly, they are present in the environment as components of bioaerosol deposited on organic dust, which can be absorbed by the respiratory tract. Among the most harmful agents that can occur in the organic dust are bacteria, fungi, allergens, endotoxins, peptidoglycans, and $\beta(1-3)$-glucans [2]. Long-term inhalation exposure to such agents may cause asthma, Sick Building Syndrome, allergic alveolitis, or Organic Dust Toxic Syndrome [3,4].

The composition and amount of organic dust to which workers are exposed depends on the type of work environment. For example, cement and composting plants have high dust concentrations in the air $[5,6]$. However, the composition and cytotoxicity of dust in each of these places are different. 
Previous studies have shown that settled dust from composting plants contain significantly more microorganisms compared to cement plants, moreover their species diversity is significantly greater [7].

The specifics of the action of biological agents relies on the fact that there is no constant relationship between their concentration or contact time and the body's response to their harmful effects. Moreover, the continuous quantitative and qualitative variability of microorganisms during the exposure of employees to these factors in the work environment has to be emphasized. Therefore, the establishment of agent-specific exposure-response relationships in workplaces is extremely complex, and hence only few health-based occupational exposure limits (OELs) were proposed for bioaerosol risk assessment [8]. As a consequence, the assessment of the occupational risk of worker exposure to biological agents is qualitative [9]. According to the EU law, i.e., 2000/54/EC Directive that outlines the principles of risk assessment, prevention, and control for biological agents [1], employers are required to assess the risks posed by biological agents. This means that they should gather information on harmful biological agents within a workplace, classify them, list the types of professional activities performed by employees that may cause exposure, and the time and extent of exposure to each agent. Any possible allergenic or toxic activity of the harmful biological agent and resulting diseases have to be determined. Employers must also analyse the registered cases of occupational diseases that were contracted by staff employed under similar work environments and the conditions of exposure to biological agents. Then proper measures to reduce the risk to the workers have to be undertaken, including elimination or substitution and exposure prevention and control. Employers should also inform and train workers and provide them with health surveillance as appropriate.

Among the measures that can minimize the consequences of health risks is the use of appropriate personal protective equipment [10]. In case of exposure to airborne biological agents, filtering facepiece respirators (FFRs) are most commonly recommended. The operating principle of such devices is the capture of bioaerosol particles from the stream of breathing air and their deposition within the respirator on the fibres of filtering nonwovens used in its construction. However, as shown in previous studies, deposited microorganisms are capable of rapid multiplication in the filtering material in conditions of high humidity (derived from exhaled air) [11]. An important factor favouring the growth of microorganisms on filtering nonwovens is organic dust, which is a source of nutrients $[12,13]$. Bacterial and fungal biofilms have been observed on FFRs used in high air-dust environments found in combined heat and power plants processing plant biomass [14]. These observations show that improperly used/stored FFRs can constitute a serious risk to the user, especially during prolonged or repeated use.

This potential threat should be considered in the occupational risk assessment associated with exposure to biological agents and the selection of respirators protecting against them. In addition, such factors as temperature, humidity, dust concentration, and the rate at which dust is deposited on the filtering surfaces of FFRs should be considered to ensure safe use of FFRs by workers. Unfortunately, little scientific research is available on the subject. Thus, the aim of the study was to evaluate the survival of selected microorganisms (Escherichia coli, Candida albicans, and Aspergillus niger) on the nonwovens used in the construction of FFRs (melt-blown, spun-bonded, needle-punched) in the presence of dust originating from work environments (cement and composting plants) and determine how joined presence of dust and microorganisms may affect the filtration efficiency of such materials.

\section{Materials and Methods}

\subsection{Dust}

Two types of dust, A and B, were studied. Dust A, with high microbial contamination (total number of microorganisms $1.38 \times 10^{8} \pm 1.27 \times 10^{7} \mathrm{CFU} / \mathrm{g}$ ) and high carbon to nitrogen ratio (C:N = 98.64), was collected from the waste homogenization hall of composting plant (Łódź, Łódź province, Poland). Dust B, with low microbial contamination $\left(2.10 \times 10^{3} \pm 1.77 \times 10^{2} \mathrm{CFU} / \mathrm{g}\right)$ and low carbon to nitrogen ratio $(\mathrm{C}: \mathrm{N}=10.71)$, was collected from the clinker transporting conveyor 
hall at cement plant (Chełm, Lublin providence, Poland). Detailed microbiological, chemical, and toxicological characterization of the studied dust types has been published in [7]. Prior to testing, collected dust samples ( 3 of each type) were subsequently sterilized for $15 \mathrm{~min}$ at $115^{\circ} \mathrm{C}$ and dried for $24 \mathrm{~h}$ at $70{ }^{\circ} \mathrm{C}$ under reduced pressure of 100 mbar in drying chamber (VD 53, Binder, Germany). An averaged specimen consisting of dust mixed at equal ratios from each sample was then prepared.

\subsection{Filtering Nonwovens}

Three types of polypropylene nonwovens typically used in the construction of FFRs were selected to test the survivability of microorganisms in the presence of dust. The characteristics of the selected nonwovens are shown in Table 1.

Table 1. Characteristics of filtering nonwovens.

\begin{tabular}{cccc}
\hline $\begin{array}{c}\text { Nonwoven Type } \\
\text { Designation }\end{array}$ & Nonwoven Type & Function in FFR Structure & $\begin{array}{c}\text { Nominal Surface } \\
\text { Mass, G/M }\end{array}$ \\
\hline MB & melt-blown, electret & high-efficiency filtration & 90 \\
\hline SB & spun-bonded & $\begin{array}{c}\text { pre-filtration of coarse dust } \\
\text { particles }\end{array}$ & 20 \\
\hline NP & $\begin{array}{c}\text { needle-punched, } \\
\text { calandered }\end{array}$ & $\begin{array}{c}\text { stiffening of the FFR } \\
\text { structure }\end{array}$ & 110 \\
\hline
\end{tabular}

\subsection{Dust Deposition in the Fibres of Filtering Nonwovens}

The samples for the study were prepared according to the methodology described in Majchrzycka et al. [15]. The filtering nonwovens were cut into circles with an area of $79 \mathrm{~cm}^{2}$ and subsequently placed in a dust chamber. There, air-dust mixture was passed through the nonwovens with a constant volumetric flow rate of $95 \pm 5 \mathrm{~L} / \mathrm{min}$. Gravimetric method was used to establish the loading time. The amount of dust introduced to the dust chamber was adjusted so that the mass deposited on the absolute filter for 4 min was close to the mass of dust that would accumulate on the filtering layers of half-mask when used in workplace with dust concentration at an occupational exposure limit level for inhalable dust, i.e., $4 \mathrm{mg} / \mathrm{m}^{3}$ [16]. Half of the loading time (2 min) was used to achieve samples corresponding to average dust concentration at the workplace.

Samples of filtering nonwovens were weighed before and after dust deposition and the dust content $\left(D_{p}\right)$ was calculated according to the formula:

$$
D_{p}=\frac{m_{p}-m}{m} \times 100 \%
$$

where: $m_{p}$-mass of the sample after dust deposition (mg), $m$-mass of the sample prior to dust deposition (mg).

\subsection{Microorganisms}

Three strains from the collection of pure American Type Culture Collection (ATCC): Escherichia coli (ATCC 10536), Candida albicans (ATCC 10231), and Aspergillus niger (ATCC 16404) were used to assess the survival of microorganisms on dust-loaded filtering nonwovens. The strains were selected based on taxonomic variety (Gram-positive cocci, yeast, and mould) and their ability to survive in the environment by forming spores (A. niger) or just through vegetative cells (E. coli and C. albicans). In addition, Directive 2000/54/EC has also classified E. coli and C. albicans species in group 2 of health hazards, while $A$. niger can induce occupational allergy and infections in people with weakened immune systems [17]. Hence these species can be potentially hazardous to employees in various working environments. Bacteria and fungi were prepared by inoculating $50 \mathrm{~mL}$ of sterile TSB medium (Tryptic Soy Broth, Merck, Darmstadt, Germany) and yeast strains in MEB medium (Malt Extract 
Broth, Merck, Darmstadt, Germany), and next incubating at $37 \pm 2{ }^{\circ} \mathrm{C}$ for $24-48 \mathrm{~h}$. Mould inoculum was obtained by washing spores from A. niger culture (MEA-Malt Extract Agar, Merck, Darmstadt, Germany, 5 days at $27 \pm 2{ }^{\circ} \mathrm{C}$,) with MEB medium. Inocula at a density of $2.17 \times 10^{7} \mathrm{CFU} / \mathrm{mL}$ (C. albicans), $2.67 \times 10^{7} \mathrm{CFU} / \mathrm{mL}$ (A. niger), and $5.3 \times 10^{9} \mathrm{CFU} / \mathrm{mL}$ (E. coli) were obtained. To assess the impact of the growth of microorganisms on the development of microbial biofilm and the filtration efficiency of dust-loaded nonwovens, a mixed culture, in equal volumetric ratios, was prepared as described above.

\subsection{Assessment of the Survival of Microorganisms on Dust-Loaded Nonwovens}

Nonwovens containing different levels of dust were used to assess the survival of the selected microorganism. Dust-loaded nonwovens of an area of $4 \mathrm{~cm}^{2}$ were cut from the previously prepared samples and $100 \mu \mathrm{L}$ of inocula were applied to each sample. The samples were then placed in sterile Petri dishes and incubated in a climatic chamber (Binder-720, Tuttlingen, Germany) at $30 \pm 2{ }^{\circ} \mathrm{C}$ and relative humidity of $80 \%$ for $8 \mathrm{~h}$. The incubation time of the tests corresponded to the use of an FFR during one work-shift.

We used the static quantitative method from the AATCC 100-2004 'Antimicrobial Finishes of Textile Materials' [18], to determine microorganism survival. Samples of nonwovens were tested immediately after inoculation (at $\mathrm{t}=0 \mathrm{~h}$ ) and after $8 \mathrm{~h}$ of incubation. The nonwovens were placed in plastic containers with $50 \mathrm{ml}$ of sterile $0.85 \%$ saline and shaken for $5 \mathrm{~min}$. Next, serial dilutions of the samples were made in $0.85 \%$ saline (from $10^{-2}$ to $10^{-6}$ ), and $1 \mathrm{ml}$ or $0.1 \mathrm{ml}$ of the appropriate dilutions was placed onto sterile Petri dishes, covered with TSA semi-solid medium (Tryptic Soy Agar, Merck, Darmstadt, Germany) for bacteria and MEA (Malt Extract Agar, Merck, Darmstadt, Germany) for yeasts and moulds. The plates were incubated at $37 \pm 2{ }^{\circ} \mathrm{C}$ for $24-48 \mathrm{~h}$ (bacteria, yeasts) and at $27 \pm 2{ }^{\circ} \mathrm{C}$ for $72 \mathrm{~h}$ (moulds). Following incubation, colonies were counted (the result is given in CFU/sample). The tests were carried out in three independent repetitions for each variant of nonwoven, dust-type, and dust deposition time (total of 45 samples were obtained for every test variant).

The microbial survival rate (survivability) $N$ for the nonwoven tested after $8 \mathrm{~h}$ of incubation was calculated according to the formula:

$$
N=\frac{N_{t}}{N_{0}} \times 100 \%
$$

where: $N_{0}$-the number of microorganisms present on the filtering nonwoven at $\mathrm{t}=0 \mathrm{~h}, \mathrm{~N}_{t}$-the number of microorganisms present on the filtering nonwoven after $8 \mathrm{~h}$ incubation (CFU/sample).

\subsection{Microscopic Assessment of Biofilms of Dust-Loaded Filtering Fibres}

To assess the development of microbial biofilm, we used nonwoven samples, which were subjected to dust for 4 min (as described in Section 2.3) and then inoculated with a mixed culture (Section 2.4). Samples prepared in this way were stored in a climatic chamber (Binder, Tuttlingen, Germany) under relative humidity of $80 \pm 2 \%$ and at a temperature of $30 \pm 2{ }^{\circ} \mathrm{C}$, for a duration of 7 days. Dust-loaded nonwovens without microorganisms and control samples without dust were also investigated. Analysis of biofilm development was carried out using a scanning electron microscope (SEM) (HITACHI SEM SU8010, Hitachi High-technology Corporation, Tokyo, Japan) following prior sputtering with gold (Q150T ES, Quorum Technologies, Lewes, UK).

\subsection{The Influence of Microbial Growth on Nanoparticles and Submicron Particles Penetration through Filtering Nonwovens}

To determine how joint presence of dust and microorganisms may affect the filtration efficiency of FFRs, we decided to measure the penetration index of sodium chloride $(\mathrm{NaCl})$ nanoparticles and submicron particles of MB nonwovens, which are responsible for high-efficiency filtration. The samples were subjected to dust for $4 \mathrm{~min}$ (as described in Section 2.3) and then inoculated with a mixed culture 
(Section 2.4). After inoculation, the samples were stored in a climatic chamber (Binder, Tuttlingen, Germany) under relative humidity of $80 \pm 2 \%$ and at a temperature of $30 \pm 2{ }^{\circ} \mathrm{C}$ for 7 days. Experiments were carried out on a test stand consisting of a Constant Flow Atomizer (3076, TSI, Shoreview, MN, USA), air purification system with a flow regulator (3074B, TSI, Shoreview, MN, USA), aerosol dryer (3062, TSI, Shoreview, MN, USA) and neutralizer (3077, TSI, Shoreview, MN, USA), scanning mobility particle sizer with differential mobility analyser (3080, TSI, Shoreview, MN, USA), condensation particle counter (3775, TSI, Shoreview, MN, USA), and pneumatic test chamber.

A dry and neutralised test aerosol containing sodium chloride particles (size range 7-270 nm) was passed at a predetermined flow rate $(47.5 \mathrm{~L} / \mathrm{min})$ through the filtering nonwoven mounted in a sample holder. Air samples were collected downstream of the sample, and then directed to an electrostatic particle classifier and a condensation particle counter to determine number and size of $\mathrm{NaCl}$ particles penetrating through the sample. Each of the results was calculated as the arithmetic mean over three measurements. Number of $\mathrm{NaCl}$ particles upstream of the sample was determined after each measurement. Then, penetration index was calculated according to the formula:

$$
N=\frac{N_{d}}{N_{u}} \times 100 \%
$$

where: $N_{d}$-number of particles downstream of the sample, $N_{u}$-number of particles upstream of the sample.

\subsection{Statistical Analysis}

Statistical analyses were performed using STATISTICA 13.1 software (Statsoft, Tulsa, OK, USA). Descriptive statistics for all variables of interest were calculated. A $t$-test at the significance level 0.05 was performed to compare microorganism numbers on the nonwovens after inoculation $(t=0 \mathrm{~h}$ and after $8 \mathrm{~h}$ of incubation. One-way analysis of variance (ANOVA) at the significance level 0.05 was performed to identify statistical differences between microorganism numbers on different types of nonwovens with medium and high dust levels. When statistical differences were detected $(p<0.05)$, mean values were compared using Tukey's post hoc procedure at the significance level 0.05 .

\section{Results and Discussion}

\subsection{Deposition of Dust on Filtering Nonwovens}

The dust content in the samples varied and it depended on the deposition time and the type of the filtering material (Table 2).

Table 2. Dust content in the nonwoven samples.

\begin{tabular}{cccc}
\hline \multirow{2}{*}{$\begin{array}{c}\text { Nonwoven Type } \\
\text { Dust Type }\end{array}$} & $\begin{array}{c}\text { Mass of Dust Deposited in the Nonwoven (Deposition Time), Mg/ } \\
\text { Dust Content in the Filtering Nonwoven, \% }\end{array}$ \\
\cline { 3 - 4 } & & Medium (2 min) & High (4 min) \\
\hline \multirow{2}{*}{ MB } & A & $15.3 / 5.9$ & $35.3 / 13.5$ \\
& B & $37.9 / 2.0$ & $89.2 / 5.5$ \\
SB & A & $6.0 / 9.6$ & $11.7 / 14.4$ \\
& B & $13.2 / 4.8$ & $19.6 / 8.5$ \\
NP & A & $6.3 / 1.6$ & $29.0 / 4.1$ \\
& B & $12.3 / 0.8$ & $40.1 / 3.3$ \\
\hline
\end{tabular}

A—dust from a composting plant; B-dust collected in the cement plant.

Scanning electron microscopy (SEM) was employed to investigate the deposition of dust in the structure of filtering nonwovens (Figure 1). 

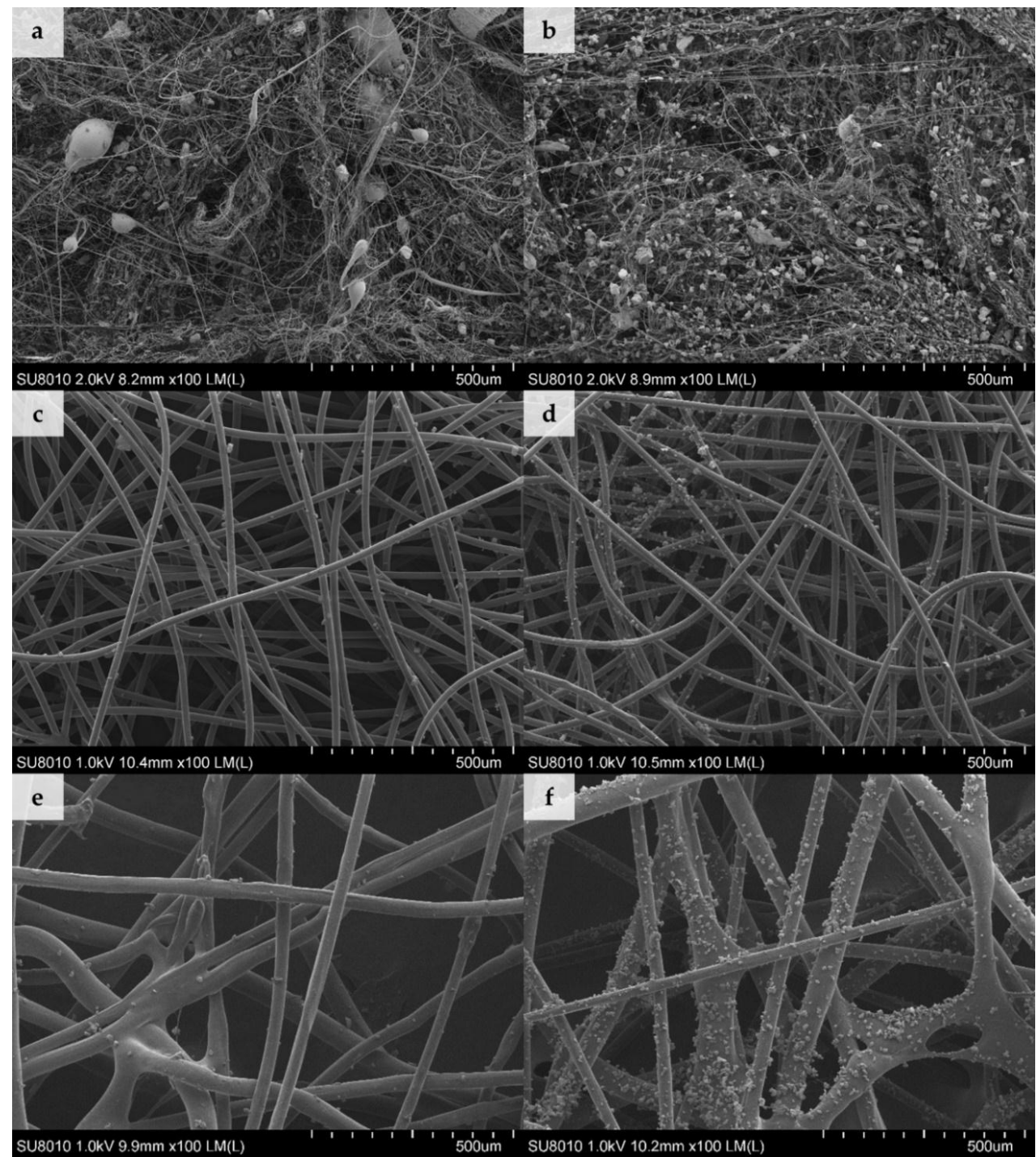

Figure 1. Scanning electron microscopy (SEM) images of nonwovens loaded with dust for 4 min(a) MB with dust $A,($ b) MB with dust $B$, (c) SB with dust A, (d) SB with dust B, (e) NP with dust A, and (f) NP with dust $B(100 \times$ magnification).

According to the filtration theory diameters of the elementary fibres, the degree of packing of fibres in the filtering material and the presence of electrostatic charge are among the factors that determine the filtration efficiency of the filtering nonwovens [19]. Our results on the amount of dust deposited in nonwovens (Table 2) are in agreement with those findings. The highest dust contents were observed for densely-packed electret MB nonwovens (Figure 1a-b) with the lowest average fiber diameter of $0.78 \pm 0.54 \mu \mathrm{m}$ (fibre diameter distribution described by a log-normal function). By contrast, the average diameter of the SB nonwoven fibres (Figure 1c-d) was $18.36 \pm 0.88 \mu \mathrm{m}$ (following a normal distribution) and NP nonwoven fibres (Figure 1e-f) was $41.93 \pm 13.02 \mu \mathrm{m}$ (following a bimodal distribution with two well distinguished peaks at $31.53 \pm 8.53 \mu \mathrm{m}$ and $55.62 \pm 10.89 \mu \mathrm{m})$. In this case the amount of deposited dust was between $55-78 \%$ lower than for MB nonwoven, which can be associated with larger diameter of fibers, as well as the lack of electrostatic charges in SB and NP nonwovens.

The average size of dust particles from composting plant was $8.37 \pm 5.16 \mu \mathrm{m}$ and was similar to the one collected from the cement plant $(8.92 \pm 6.57 \mu \mathrm{m})$. The lack of differences between particle sizes was probably due to the fact that both samples were sieved and dried before the experiment, 
which might have affect their physical sizes. In the case of SB and NP nonwovens, dust agglomerates and individual grains of dimensions ranging from $0.83 \mu \mathrm{m}$ to $37.50 \mu \mathrm{m}$ were found to be fixed on the surface of the fibres, regardless of the dust type (Figure 1c-f). On the other hand, dust agglomerates were deposited on MB nonwovens in two ways: smaller grains, of dimensions ranging from $0.42 \mu \mathrm{m}$ to $0.83 \mu \mathrm{m}$, were attached directly to the fibres; while bigger agglomerates, with diameters up to $32.9 \mu \mathrm{m}$, were embedded in-between entangled fibres and were also simultaneously attached to several surrounding fibres (Figure 1a-b).

Despite the fact that conditions used for deposition of both types of dust were identical (time and concentration), significant differences in the quantities of dust deposited on the same nonwoven type were observed (Table 2). For type A dust, the increase in sample mass was twice that of type B dust, independent of the nonwoven used. The high density of agglomerates observed in SEM images, with dust from the cement plant, may have resulted from a greater hygroscopicity of cement dust and its effect on deposition of particles on the fibers in the presence of moisture in an air stream [20].

\subsection{Survival of Microorganisms on Dust-Loaded Filtering Nonwovens}

Number of $E$. coli bacteria on all control nonwovens studied at $\mathrm{t}=0 \mathrm{~h}$ was at a similar level and equalled $7.34 \times 10^{7}-1.74 \times 10^{8} \mathrm{CFU} /$ sample. After $8 \mathrm{~h}$ incubation, a greater number of bacteria was noted on all samples (Table 3). The number of E. coli bacteria on individual nonwovens in the presence of dust from the composting plant increased from $2.80 \times 10^{7}-1.34 \times 10^{8} \mathrm{CFU} /$ sample at $\mathrm{t}=0 \mathrm{~h}$ to $3.26 \times 10^{8}-3.78 \times 10^{9} \mathrm{CFU} /$ sample after $8 \mathrm{~h}$. On the other hand, in the presence of dust from the cement plant the number of $E$. coli bacteria was in the range of $5.12 \times 10^{4}-1.11 \times 10^{8} \mathrm{CFU} /$ sample at $\mathrm{t}=0 \mathrm{~h}$ and $8.22 \times 10^{7}-2.19 \times 10^{9} \mathrm{CFU} /$ sample after $8 \mathrm{~h}$. Statistically significant differences in the number of $E$. coli bacteria after $8 \mathrm{~h}$ (t-test) were noted for nonwovens with dust from the composting plant: MB nonwoven (dust concentration of $15.3 \mathrm{mg}$ ), SB nonwoven (both concentrations), NP nonwoven $(6.3 \mathrm{mg})$, as well as for NP nonwoven with dust from the cement plant (40.1 $\mathrm{mg})$. In the Tukey test of multiple comparisons of all variants after $8 \mathrm{~h}$, significant differences in the E. coli number with respect to the tested variants: $f, g, h, i, j, l, n$, and o were found for the NP nonwoven control (Table 3).

Survival rate of E. coli bacteria on control nonwovens ranged from 228 to $5692 \%$ (Figure 2). On MB nonwoven (in the presence of both dust types) and SB nonwoven (composting plant dust), it increased to the levels of 261-150,946\%. In contrast, on NP nonwoven (in the presence of both dust types) and SB nonwoven (cement plant dust), E. coli bacteria survivability was lower than on control samples and ranged from $136-2649 \%$. Comparing the increase in survivability on nonwovens between the different dust concentrations, it can be concluded that higher dust concentration from the composting plant increased the survival rate of $E$. coli bacteria by $181-10,333 \%$, while it increased the survival rate by $26-143,040 \%$ (Figure 2) in samples from the cement plant.

The number of $C$. albicans on control nonwovens at $\mathrm{t}=0 \mathrm{~h}$ was at similar levels and equalled $3.02 \times 10^{5}-5.02 \times 10^{5} \mathrm{CFU} /$ sample. In the presence of dust from the composting plant, it increased to $3.06 \times 10^{5}-6.80 \times 10^{5} \mathrm{CFU} /$ sample at $\mathrm{t}=0 \mathrm{~h}$ and to $1.94 \times 10^{6}-2.72 \times 10^{6} \mathrm{CFU} /$ sample after $8 \mathrm{~h}$ of incubation. By contrast, in the presence of dust from the cement plant, the number of $C$. albicans ranged from $2.66 \times 10^{5}$ to $6.92 \times 10^{5} \mathrm{CFU} /$ sample at $\mathrm{t}=0 \mathrm{~h}$ and $8.38 \times 10^{4}-1.37 \times 10^{6} \mathrm{CFU} /$ sample after $8 \mathrm{~h}$ of incubation (Table 4). Statistically significant differences ( $t$-test) in $C$. albicans numbers, after $8 \mathrm{~h}$ of incubation, were noted for all nonwovens in the presence of dust, except for SB (dust concentration $19.6 \mathrm{mg})$ and NP $(40.1 \mathrm{mg})$ nonwovens containing dust from the cement plant. Statistically significant differences (Tukey test) in the number of $C$. albicans were found after $8 \mathrm{~h}$ for variants: $a, b, d, e, g, h, i, j$, $\mathrm{k}, \mathrm{m}, \mathrm{n}$, and o (Table 4). 
Table 3. Number of Escherichia coli bacteria on the filtering nonwovens depending on dust type and content.

\begin{tabular}{|c|c|c|c|c|c|}
\hline $\begin{array}{l}\text { Nonwoven } \\
\text { Type }\end{array}$ & Dust Type & Dust Content & Variant & $\begin{array}{l}\text { Number of } \\
\text { Microorganisms at } 0 \mathrm{~h} \text {, } \\
\text { CFU/Sample }\end{array}$ & $\begin{array}{c}\text { Number of } \\
\text { Microorganisms at } 8 \mathrm{~h}, \\
\text { CFU/Sample }\end{array}$ \\
\hline \multirow{5}{*}{ MB } & $\mathrm{C}$ & 0 & a & $\begin{array}{l}\text { M: } 9.26 \times 10^{7} \\
\text { SD: } 5.29 \times 10^{7}\end{array}$ & $\begin{array}{l}\text { M: } 1.17 \times 10^{9 \#} \\
\text { SD: } 7.86 \times 10^{8}\end{array}$ \\
\hline & \multirow{2}{*}{ A } & medium & $\mathrm{b}$ & $\begin{array}{l}\text { M: } 7.70 \times 10^{7} \\
\text { SD: } 7.60 \times 10^{7}\end{array}$ & $\begin{array}{l}\text { M: } 1.97 \times 10^{9 \#} \\
\text { SD: } 9.59 \times 10^{8}\end{array}$ \\
\hline & & high & c & $\begin{array}{l}\text { M: } 2.80 \times 10^{7} \\
\text { SD: } 1.73 \times 10^{7}\end{array}$ & $\begin{array}{l}\text { M: } 3.78 \times 10^{9 \#} \\
\text { SD: } 2.09 \times 10^{9}\end{array}$ \\
\hline & \multirow{2}{*}{ B } & medium & d & $\begin{array}{l}\text { M: } 2.12 \times 10^{7} \\
\text { SD: } 1.16 \times 10^{7}\end{array}$ & $\begin{array}{l}\text { M: } 2.19 \times 10^{9} \\
\text { SD: } 2.57 \times 10^{9}\end{array}$ \\
\hline & & high & e & $\begin{array}{l}\text { M: } 5.12 \times 10^{4 f} \\
\text { SD: } 3.99 \times 10^{4}\end{array}$ & $\begin{array}{l}\text { M: } 8.22 \times 10^{7 k} \\
\text { SD: } 8.51 \times 10^{7}\end{array}$ \\
\hline \multirow{5}{*}{ SB } & $\mathrm{C}$ & 0 & $\mathrm{f}$ & $\begin{array}{l}\text { M: } 1.74 \times 10^{8 \mathrm{e}} \\
\text { SD: } 1.51 \times 10^{8}\end{array}$ & $\begin{array}{l}\text { M: } 3.92 \times 10^{8 \mathrm{k}} \\
\text { SD: } 3.13 \times 10^{8}\end{array}$ \\
\hline & \multirow{2}{*}{ A } & medium & g & $\begin{array}{l}\text { M: } 1.34 \times 10^{8} \\
\text { SD: } 8.51 \times 10^{7}\end{array}$ & $\begin{array}{l}\text { M: } 3.26 \times 10^{8 \# k} \\
\text { SD: } 1.62 \times 10^{8}\end{array}$ \\
\hline & & high & $\mathrm{h}$ & $\begin{array}{l}\text { M: } 1.30 \times 10^{8} \\
\text { SD: } 9.41 \times 10^{7}\end{array}$ & $\begin{array}{l}\text { M: } 4.38 \times 10^{8 \# k} \\
\text { SD: } 6.18 \times 10^{7}\end{array}$ \\
\hline & \multirow{2}{*}{ B } & medium & $\mathrm{i}$ & $\begin{array}{l}\text { M: } 1.11 \times 10^{8} \\
\text { SD: } 5.05 \times 10^{7}\end{array}$ & $\begin{array}{l}\text { M: } 1.46 \times 10^{8 \mathrm{k}} \\
\text { SD: } 5.52 \times 10^{7}\end{array}$ \\
\hline & & high & j & $\begin{array}{l}\text { M: } 1.05 \times 10^{8} \\
\text { SD: } 7.30 \times 10^{7}\end{array}$ & $\begin{array}{l}\text { M: } 1.46 \times 10^{8 \mathrm{k}} \\
\text { SD: } 7.10 \times 10^{7}\end{array}$ \\
\hline \multirow{5}{*}{ NP } & $\mathrm{C}$ & 0 & k & $\begin{array}{l}\text { M: } 7.34 \times 10^{7} \\
\text { SD: } 3.15 \times 10^{7}\end{array}$ & $\begin{array}{l}\text { M: } 5.04 \times 10^{9 \mathrm{f}, \mathrm{g}, \mathrm{h}, \mathrm{i}, \mathrm{j}, \mathrm{l}, \mathrm{n}, \mathrm{o}} \\
\text { SD: } 5.00 \times 10^{9}\end{array}$ \\
\hline & \multirow{2}{*}{ A } & medium & 1 & $\begin{array}{l}\text { M: } 7.04 \times 10^{7} \\
\text { SD: } 5.66 \times 10^{7}\end{array}$ & $\begin{array}{l}\text { M: } 8.22 \times 10^{8 * k} \\
\text { SD: } 5.82 \times 10^{8}\end{array}$ \\
\hline & & high & $\mathrm{m}$ & $\begin{array}{l}\text { M: } 1.31 \times 10^{8} \\
\text { SD: } 1.28 \times 10^{8}\end{array}$ & $\begin{array}{l}\text { M: } 3.72 \times 10^{9} \\
\text { SD: } 3.60 \times 10^{9}\end{array}$ \\
\hline & \multirow{2}{*}{ B } & medium & $\mathrm{n}$ & $\begin{array}{l}\text { M: } 8.96 \times 10^{7} \\
\text { SD: } 6.92 \times 10^{7}\end{array}$ & $\begin{array}{l}\text { M: } 1.58 \times 10^{8 \mathrm{k}} \\
\text { SD: } 3.11 \times 10^{7}\end{array}$ \\
\hline & & high & o & $\begin{array}{l}\text { M: } 1.58 \times 10^{7 a} \\
\text { SD: } 1.15 \times 10^{7}\end{array}$ & $\begin{array}{l}\text { M: } 1.79 \times 10^{8 \# k} \\
\text { SD: } 1.17 \times 10^{8}\end{array}$ \\
\hline
\end{tabular}

C—control; A—dust from a composting plant; B—dust collected in the cement plant; M-mean value, SD—standard deviation, \#-statistically significant differences between bacteria number at $\mathrm{t}=0 \mathrm{~h}$ and after $8 \mathrm{~h}$ of incubation for all variants; ( $t$-test, $\alpha=0.05)$; a-o in the upper index-the variants, for which statistically significant differences between microorganism numbers on nonwovens with different dust content were found (Tukey test, $\alpha=0.05$ ). 


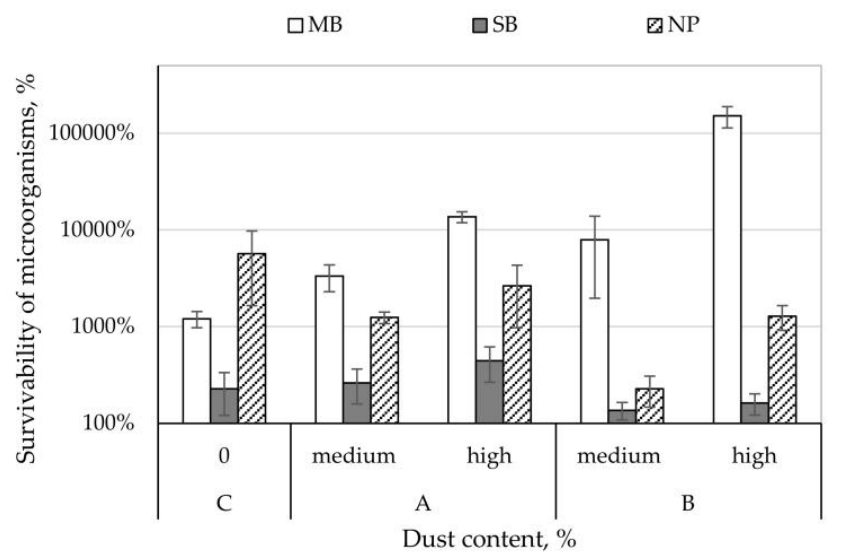

Figure 2. Survivability of Escherichia coli bacteria on the filtering nonwovens depending on dust type and content.

Table 4. Number of Candida albicans on filtering nonwovens depending on dust type and content.

\begin{tabular}{|c|c|c|c|c|c|}
\hline $\begin{array}{l}\text { Nonwoven } \\
\text { Type }\end{array}$ & Dust Type & Dust Content & Variant & $\begin{array}{l}\text { Number of } \\
\text { Microorganisms at } 0 \mathrm{~h}, \\
\text { CFU/Sample }\end{array}$ & $\begin{array}{l}\text { Number of } \\
\text { Microorganisms at } 8 \mathrm{~h} \text {, } \\
\text { CFU/Sample }\end{array}$ \\
\hline \multirow{5}{*}{ MB } & C & 0 & $\mathrm{a}$ & $\begin{array}{l}\text { M: } 5.02 \times 10^{5} \\
\text { SD: } 5.93 \times 10^{4}\end{array}$ & $\begin{array}{l}\text { M: } 3.82 \times 10^{6 \# \mathrm{~d}, \mathrm{e}, \mathrm{i}, \mathrm{i}, \mathrm{m}, \mathrm{n}, \mathrm{o}} \\
\text { SD: } 2.49 \times 10^{6}\end{array}$ \\
\hline & \multirow{2}{*}{ A } & medium & $\mathrm{b}$ & $\begin{array}{l}\text { M: } 3.14 \times 10^{5} \\
\text { SD: } 5.37 \times 10^{4}\end{array}$ & $\begin{array}{l}\text { M: } 2.72 \times 10^{6 \# \mathrm{e}, \mathrm{j}} \\
\text { SD: } 2.77 \times 10^{5}\end{array}$ \\
\hline & & high & c & $\begin{array}{l}\text { M: } 4.00 \times 10^{5} \\
\text { SD: } 5.34 \times 10^{4}\end{array}$ & $\begin{array}{l}\text { M: } 1.94 \times 10^{6 \#} \\
\text { SD: } 7.02 \times 10^{5}\end{array}$ \\
\hline & \multirow{2}{*}{ B } & medium & d & $\begin{array}{l}\text { M: } 2.66 \times 10^{5 \mathrm{k}, \mathrm{i}} \\
\text { SD: } 1.15 \times 10^{5}\end{array}$ & $\begin{array}{l}\text { M: } 1.03 \times 10^{6 \# a} \\
\text { SD: } 2.93 \times 10^{5}\end{array}$ \\
\hline & & high & $\mathrm{e}$ & $\begin{array}{l}\text { M: } 4.06 \times 10^{5} \\
\text { SD: } 1.07 \times 10^{5}\end{array}$ & $\begin{array}{l}\text { M: } 8.38 \times 10^{4 \# a, b, g, h, k} \\
\quad \text { SD: } 3.04 \times 10^{4}\end{array}$ \\
\hline \multirow{5}{*}{ SB } & C & 0 & $\mathrm{f}$ & $\begin{array}{l}\text { M: } 4.18 \times 10^{5} \\
\text { SD: } 1.70 \times 10^{5}\end{array}$ & $\begin{array}{l}\text { M: } 2.08 \times 10^{6 \#} \\
\text { SD: } 1.03 \times 10^{6}\end{array}$ \\
\hline & \multirow{2}{*}{ A } & medium & g & $\begin{array}{l}\text { M: } 4.18 \times 10^{5} \\
\text { SD: } 2.29 \times 10^{5}\end{array}$ & $\begin{array}{l}\text { M: } 2.72 \times 10^{6 \# \mathrm{e}, \mathrm{j}} \\
\text { SD: } 1.26 \times 10^{6}\end{array}$ \\
\hline & & high & $\mathrm{h}$ & $\begin{array}{l}\text { M: } 6.80 \times 10^{5 d} \\
\text { SD: } 4.35 \times 10^{5}\end{array}$ & $\begin{array}{l}\text { M: } 2.66 \times 10^{6 \# \mathrm{e}} \\
\text { SD: } 1.45 \times 10^{6}\end{array}$ \\
\hline & \multirow{2}{*}{ B } & medium & $\mathrm{i}$ & $\begin{array}{l}\text { M: } 6.92 \times 10^{5 \mathrm{~d}, \mathrm{k}, \mathrm{m}, \mathrm{n}} \\
\text { SD: } 2.80 \times 10^{5}\end{array}$ & $\begin{array}{l}\text { M: } 5.38 \times 10^{5 \# a} \\
\text { SD: } 3.08 \times 10^{5}\end{array}$ \\
\hline & & high & $\mathrm{j}$ & $\begin{array}{l}\text { M: } 4.02 \times 10^{5} \\
\text { SD: } 1.04 \times 10^{5}\end{array}$ & $\begin{array}{l}\text { M: } 2.86 \times 10^{5 a, b, g, k} \\
\text { SD: } 1.49 \times 10^{5}\end{array}$ \\
\hline \multirow{5}{*}{ NP } & C & 0 & k & $\begin{array}{l}\text { M: } 3.02 \times 10^{5 i, d} \\
\text { SD: } 1.06 \times 10^{5}\end{array}$ & $\begin{array}{l}\text { M: } 2.88 \times 10^{6 \# e, j} \\
\text { SD: } 1.67 \times 10^{6}\end{array}$ \\
\hline & \multirow{2}{*}{ A } & medium & 1 & $\begin{array}{l}\text { M: } 3.76 \times 10^{5} \\
\text { SD: } 1.22 \times 10^{5}\end{array}$ & $\begin{array}{l}\text { M: } 2.28 \times 10^{6 \#} \\
\text { SD: } 1.07 \times 10^{6}\end{array}$ \\
\hline & & high & $\mathrm{m}$ & $\begin{array}{l}\text { M: } 3.06 \times 10^{5 i} \\
\text { SD: } 6.47 \times 10^{4}\end{array}$ & $\begin{array}{l}\text { M: } 8.18 \times 10^{5 \# a} \\
\text { SD: } 3.26 \times 10^{5}\end{array}$ \\
\hline & \multirow[b]{2}{*}{ B } & medium & $\mathrm{n}$ & $\begin{array}{l}\text { M: } 3.10 \times 10^{5 i} \\
\text { SD: } 5.57 \times 10^{4}\end{array}$ & $\begin{array}{l}\text { M: } 1.37 \times 10^{6 \# a} \\
\text { SD: } 4.65 \times 10^{5}\end{array}$ \\
\hline & & high & $\mathrm{o}$ & $\begin{array}{l}\text { M: } 3.94 \times 10^{5} \\
\text { SD: } 6.50 \times 10^{4}\end{array}$ & $\begin{array}{l}\text { M: } 9.10 \times 10^{5 a} \\
\text { SD: } 1.28 \times 10^{6}\end{array}$ \\
\hline
\end{tabular}

C—control; A—dust from a composting plant; B-dust collected in the cement plant; M-mean value, SD-standard deviation, \#-statistically significant differences between bacteria number at $t=0 \mathrm{~h}$ and after $8 \mathrm{~h}$ of incubation for all variants; ( $t$-test, $\alpha=0.05)$; a-o in the upper index-the variants, for which statistically significant differences between microorganisms numbers on nonwovens with different dust content were found (Tukey test, $\alpha=0.05$ ). 
The survivability of C. albicans on control nonwovens ranged from $543 \%$ (SB nonwoven) to $885 \%$ (NP nonwoven). C. albicans survival rate on MB and SB nonwovens with dust from a composting plant with medium concentration was higher than control samples and ranged between $668-875 \%$. In contrast, for the remaining variants of the nonwovens studied, C. albicans survivability was lower than control samples and ranged from 20 to 609\% (Figure 3). Comparing the increase in survival rate between the different dust concentrations, we found that dust from the composting plant lowered the survival of $C$. albicans by $264 \%$ (SB nonwoven), 348\% (NP nonwoven), and 399\% (MB nonwoven); whilst dust from the cement plant lowered it by $6 \%$ (SB nonwoven), 229\% (NP nonwoven), and 383\% (MB nonwoven) (Figure 3).

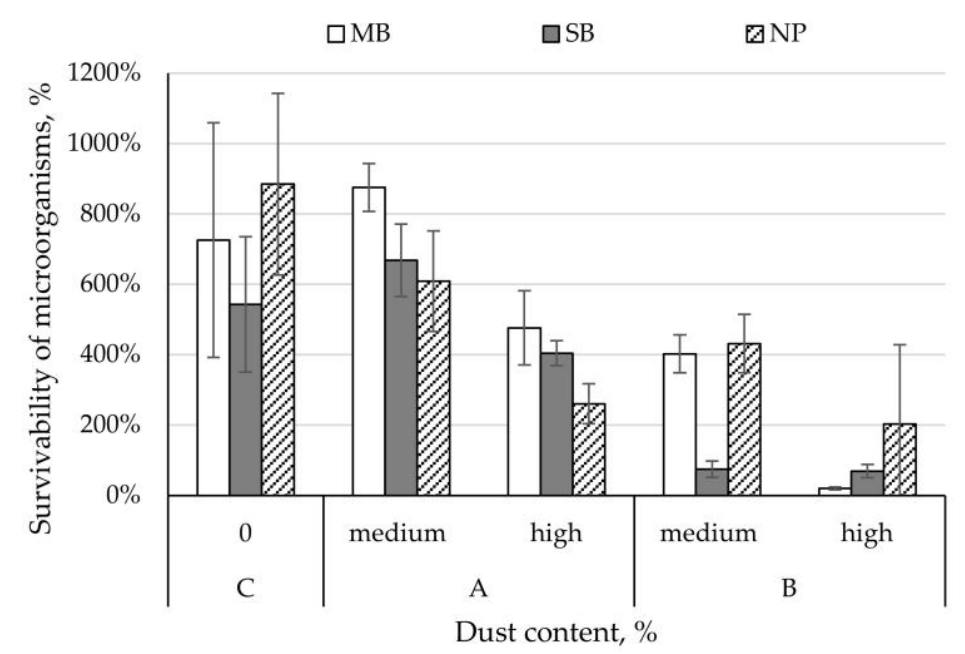

Figure 3. Survivability of Candida albicans yeasts on filtering nonwovens depending on dust-type and content.

The number of $A$. niger on control nonwovens at $t=0 \mathrm{~h}$ was at similar level and ranged from $2.14 \times 10^{5}$ to $3.26 \times 10^{5} \mathrm{CFU} /$ sample. A decrease in $A$. niger numbers was noted for all control samples after $8 \mathrm{~h}$ of incubation. The number of $A$. niger on the nonwovens at $t=0 \mathrm{~h}$ in the presence of various concentrations of dust from the composting plant was $1.44 \times 10^{5}-2.96 \times 10^{5} \mathrm{CFU} /$ sample, and after $8 \mathrm{~h}$ $7.12 \times 10^{4}-3.24 \times 10^{5} \mathrm{CFU} /$ sample. In contrast, the number of $A$. niger in the presence of dust from the cement plant ranged from $1.60 \times 10^{5}$ to $5.08 \times 10^{5} \mathrm{CFU} /$ sample at $t=0 \mathrm{~h}$, and $1.01 \times 10^{5}-3.60 \times 10^{5}$ $\mathrm{CFU} /$ sample after $8 \mathrm{~h}$ incubation (Table 5$)$. Statistically significant differences ( $t$-test) in the number of A. niger fungi after $8 \mathrm{~h}$ was noted for $\mathrm{MB}(35.3 \mathrm{mg}), \mathrm{SB}(6.0 \mathrm{and} 11.7 \mathrm{mg})$, and NP (6.3 mg) nonwovens with dust from the composting plant, and for NP $(12.3 \mathrm{mg})$ nonwoven with dust from the cement plant. Statistically significant differences (Tukey test) were seen in the number of $A$. niger for SB nonwoven in the presence of dust from the cement plant $(13.2 \mathrm{mg})$ at $t=0 \mathrm{~h}$ with respect to the remaining experimental variants. After $8 \mathrm{~h}$ incubation, significant differences in the number of these moulds were noted with respect to the remaining variants studied: $c, d, g, h, i$, and $l$. 
Table 5. Number of Aspergillus niger moulds on the filtering nonwovens depending on dust-type and content.

\begin{tabular}{|c|c|c|c|c|c|}
\hline $\begin{array}{l}\text { Nonwoven } \\
\text { Type }\end{array}$ & Dust Type & Dust Content & Variant & $\begin{array}{l}\text { Number of } \\
\text { Microorganisms at } 0 \mathrm{~h} \text {, } \\
\text { CFU/Sample }\end{array}$ & $\begin{array}{c}\text { Number of } \\
\text { Microorganisms at } 8 \mathrm{~h} \text {, } \\
\text { CFU/Sample }\end{array}$ \\
\hline \multirow{5}{*}{ MB } & $\mathrm{C}$ & 0 & a & $\begin{array}{l}\text { M: } 3.26 \times 10^{5} \\
\text { SD: } 1.00 \times 10^{5}\end{array}$ & $\begin{array}{l}\text { M: } 1.38 \times 10^{5 \# c, i} \\
\text { SD: } 4.44 \times 10^{4}\end{array}$ \\
\hline & \multirow{2}{*}{ A } & medium & $\mathrm{b}$ & $\begin{array}{l}\text { M: } 2.40 \times 10^{5 \mathrm{i}} \\
\text { SD: } 5.87 \times 10^{4}\end{array}$ & $\begin{array}{l}\text { M: } 1.88 \times 10^{5 \mathrm{ci}} \\
\text { SD: } 1.64 \times 10^{4}\end{array}$ \\
\hline & & high & c & $\begin{array}{l}\text { M: } 2.54 \times 10^{5 \mathrm{i}} \\
\text { SD: } 3.21 \times 10^{4}\end{array}$ & $\begin{array}{l}\text { M: } 3.24 \times 10^{5 \# a, b, e-h, j-o} \\
\text { SD: } 2.61 \times 10^{4}\end{array}$ \\
\hline & \multirow{2}{*}{ B } & medium & d & $\begin{array}{l}\text { M: } 2.42 \times 10^{5 i} \\
\text { SD: } 3.77 \times 10^{4}\end{array}$ & $\begin{array}{l}\text { M: } 2.32 \times 10^{5} \text { g-i, } 1, \mathrm{n} \\
\text { SD: } 4.87 \times 10^{4}\end{array}$ \\
\hline & & high & e & $\begin{array}{l}\text { M: } 2.22 \times 10^{5 i} \\
\text { SD: } 6.18 \times 10^{4}\end{array}$ & $\begin{array}{l}\text { M: } 1.90 \times 10^{5 c, i, l} \\
\text { SD: } 4.85 \times 10^{4}\end{array}$ \\
\hline \multirow{5}{*}{ SB } & C & 0 & $\mathrm{f}$ & $\begin{array}{l}\text { M: } 2.28 \times 10^{5 i} \\
\text { SD: } 5.17 \times 10^{4}\end{array}$ & $\begin{array}{l}\text { M: } 1.30 \times 10^{5 \# c, i} \\
\text { SD: } 3.32 \times 10^{4}\end{array}$ \\
\hline & \multirow{2}{*}{ A } & medium & g & $\begin{array}{l}\text { M: } 2.24 \times 10^{5 \mathrm{i}} \\
\text { SD: } 7.70 \times 10^{4}\end{array}$ & $\begin{array}{l}\text { M: } 9.70 \times 10^{4 \# c, d, i} \\
\text { SD: } 8.34 \times 10^{4}\end{array}$ \\
\hline & & high & $\mathrm{h}$ & $\begin{array}{l}\text { M: } 2.36 \times 10^{5 i} \\
\text { SD: } 7.44 \times 10^{4}\end{array}$ & $\begin{array}{l}\text { M: } 1.07 \times 10^{5 \# c, d, i} \\
\text { SD: } 5.59 \times 10^{4}\end{array}$ \\
\hline & \multirow{2}{*}{ B } & medium & $\mathrm{i}$ & $\begin{array}{l}\text { M: } 5.08 \times 10^{5 \mathrm{~b}-\mathrm{o}} \\
\text { SD: } 1.84 \times 10^{5}\end{array}$ & $\begin{array}{l}\text { M: } 3.60 \times 10^{5 a, b, d-o} \\
\text { SD: } 1.09 \times 10^{5}\end{array}$ \\
\hline & & high & $\mathrm{j}$ & $\begin{array}{l}\text { M: } 1.64 \times 10^{5} \\
\text { SD: } 4.16 \times 10^{4}\end{array}$ & $\begin{array}{l}\text { M: } 1.72 \times 10^{5} \\
\text { SD: } 3.56 \times 10^{4}\end{array}$ \\
\hline \multirow{5}{*}{$\mathrm{NP}$} & C & 0 & k & $\begin{array}{l}\text { M: } 2.14 \times 10^{5 \mathrm{i}} \\
\text { SD: } 7.86 \times 10^{4}\end{array}$ & $\begin{array}{l}\text { M: } 1.47 \times 10^{5 c, i} \\
\text { SD: } 6.51 \times 10^{4}\end{array}$ \\
\hline & \multirow{2}{*}{ A } & medium & 1 & $\begin{array}{l}\text { M: } 2.96 \times 10^{5 i} \\
\text { SD: } 1.16 \times 10^{5}\end{array}$ & $\begin{array}{l}\text { M: } 7.12 \times 10^{4 \# c-e, i} \\
\text { SD: } 1.17 \times 10^{4}\end{array}$ \\
\hline & & high & $\mathrm{m}$ & $\begin{array}{l}\text { M: } 1.44 \times 10^{5 \mathrm{i}} \\
\text { SD: } 7.09 \times 10^{4}\end{array}$ & $\begin{array}{l}\text { M: } 1.25 \times 10^{5 c, i} \\
\text { SD: } 4.19 \times 10^{4}\end{array}$ \\
\hline & \multirow{2}{*}{ B } & medium & $\mathrm{n}$ & $\begin{array}{l}\text { M: } 3.02 \times 10^{5 i} \\
\text { SD: } 9.42 \times 10^{4}\end{array}$ & $\begin{array}{l}\text { M: } 1.01 \times 10^{5 \# c, d, i} \\
\text { SD: } 4.71 \times 10^{4}\end{array}$ \\
\hline & & high & o & $\begin{array}{l}\text { M: } 1.60 \times 10^{5 \mathrm{i}} \\
\text { SD: } 2.92 \times 10^{4}\end{array}$ & $\begin{array}{l}\text { M: } 1.23 \times 10^{5 c, i} \\
\text { SD: } 3.50 \times 10^{4}\end{array}$ \\
\hline
\end{tabular}

C—control; A-dust from a composting plant; B-dust collected in the cement plant; M-mean value, SD—standard deviation, \#-statistically significant differences between bacteria number at $t=0 \mathrm{~h}$ and after $8 \mathrm{~h}$ of incubation for all variants; ( $t$-test, $\alpha=0.05$ ); a-o in the upper index - the variants, for which statistically significant differences between microorganisms numbers on nonwovens with different dust content were found (Tukey test, $\alpha=0.05$ ).

The survival rate of $A$. niger on control nonwovens ranged from $41 \%$ (MB nonwoven) to $68 \%$ (NP nonwoven). The $A$. niger survival rate on SB nonwovens with dust from composting plant with medium and high concentration and NP nonwovens with dust from composting plant and cement plant with medium concentration was lower than for control samples and ranged between $25-43 \%$. In contrast, for the remaining variants of nonwovens studied, $A$. niger survivability was higher than control samples and ranged from 74 to $128 \%$ (Figure 4). Comparing the increase in survival rates on nonwovens between the different dust concentrations, it can be stated that dust from the composting plant increases the survivability of $A$. niger by $3-68 \%$ and dust from the cement plant increases survival rate by $32-44 \%$; while higher concentration of dust from the cement plant on MB nonwoven lowers A. niger survival rate by $8 \%$ (Figure 4 ). 


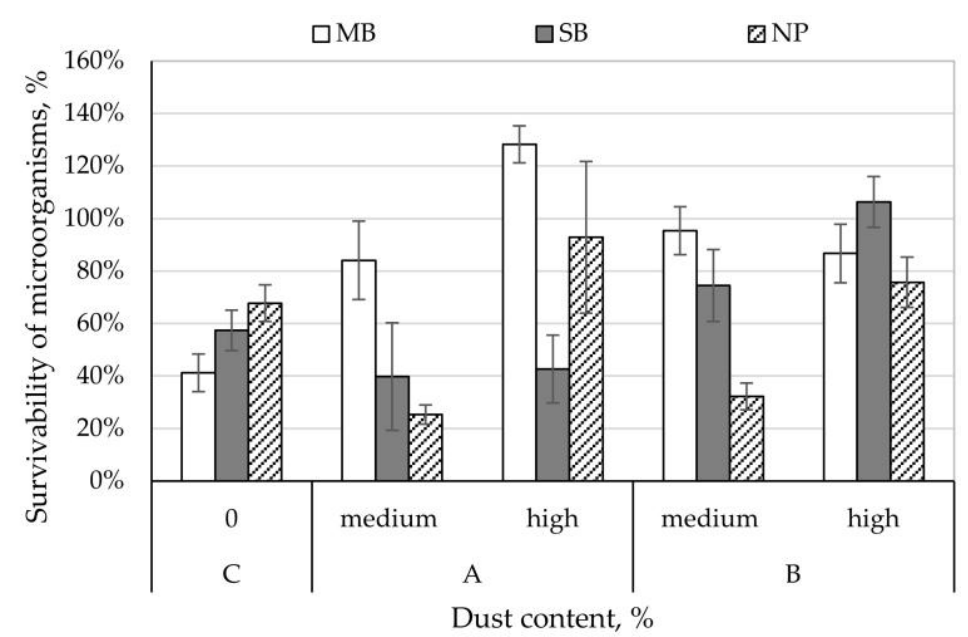

Figure 4. Survivability of Aspergillus niger moulds on filtering nonwovens depending on dust-type and content.

In this paper, we tested the survival of bacteria, yeasts, and moulds on nonwovens used for the construction of filtering half masks. These microorganisms are a health threat in many working environments. Survival, over a time-frame corresponding to a standard working shift ( $8 \mathrm{~h})$, depended on the type of nonwoven and the species of the microorganism. The highest survival rates were observed for: NP $(N=25-5692 \%)$ and MB nonwovens $(N=20-150,946 \%)$, lower for SB nonwoven ( $N=40-668 \%$ ). The lower survivability of microorganisms on SB nonwoven can be associated to its low nominal surface mass $\left(20 \mathrm{~g} / \mathrm{m}^{2}\right)$ and thus lower capacity to collect dust, which constituted a source of nutrients for microorganisms.

The degree of survival of E. coli, C. albicans, and A. niger on fibres in the presence of dust from the composting and cement plants depended not only on the microorganism, but also on the type and amount of dust. In most cases dust from the composting plant (at a concentration of 4.1-14.4\%, depending on the nonwoven) and cement plant (3.3-8.5\%) increased the survival of E. coli bacteria and $A$. niger moulds on the filtering nonwovens. Dust from the composting plant did not increase the survival of $C$. albicans, whereas dust from the cement plant significantly decreased yeast survival. Different groups of microorganisms may be sensitive to biocides in various ways (antiseptics and disinfectants). Based on varied composition of the outer cell layers, it is assumed that Gram-negative bacteria like E. coli are naturally characterized by greater resistance to harmful factors compared to Gram-positive bacteria but smaller than moulds [21]. The survivability (sensitivity) of microorganisms may be affected by many factors that were not the subject of this study, for example, the growth phase of tested microorganisms. However, it should be emphasized that more and more studies indicate not only differences in the sensitivity of individual groups of microorganisms to physical and chemical factors, but also to the occurrence of such differences in another strains of the same species. Collection strains may have different sensitivity from those isolated from the environment, the same can be true for environmental strains but isolated from various places. Such observations were made, among others, during tests of bacteria and fungi strains from ATCC collection (6 strains) and from archives and museums (32) to silver nanoparticles [22], or from ATCC collection (5) and from museums, composting plants, tanneries (18) to nonwovens with Sanitized [23]. The high carbon to nitrogen ratio (C:N $=98.64)$ in dust from the composting plant promoted growth compared to dust from the cement plant, which had a low ratio ( $\mathrm{C}: \mathrm{N} \approx 10)$. Gutarowska et al. 2018 found different levels of microbial contamination in sedimented dust samples depending on the workplace-high for samples of cereal dust from a composting plant, lower for dust from a poultry farm and the lowest from a cement plant [7]. The highest number and variety of microorganisms was found in dust from composting plant and in cereal dust, while it was lowest in the case of a cement plant. This confirms that dust 
from a composting plant is a good source of nutrients that allow the growth of microorganisms in this environment. Moreover, it may provide nutrients that induce the growth of microorganisms (reproduction of bacteria and germination of spores of moulds) on dust-loaded filtering nonwovens, which would explain that, in most cases, more intensive growth of microorganisms was observed on nonwovens loaded with composting plant dust than on those loaded with cement dust. Furthermore, the results obtained by Maus et al. indicate that atmospheric dust present on filtering materials can be a source of nutrients for $A$. niger and with adequate humidity can positively affect the survival of these microorganisms [12]. In model studies, Majchrzycka et al. found that the survival of microorganisms on filtering materials, after $24 \mathrm{~h}$ incubation at high humidity, correlated with the concentration of dust $(9-104 \% \mathrm{~m} / \mathrm{m})$ [15]. In their study they used dust from a combined heat and power plant processing plant biomass. The authors showed that in conditions of high humidity, organic dust on the filtering nonwovens increased the survival of E. coli bacteria by $410 \%$ in relation to survival of these bacteria on control nonwovens. Likewise, the present study establishes that dust from the composting and cement plants deposited on nonwoven materials for the construction of filtering half-masks increased the survival rate of the tested microorganisms by $149,743 \%$ (E. coli bacteria), $81 \%$ (A. niger moulds), and $149 \%$ (C. albicans yeasts).

\subsection{Microscopic Assessment of Biofilms on Dust-Loaded Filtering Nonwovens}

The ability of microorganisms to grow on nonwovens loaded with different types of dust was also confirmed using a scanning electron microscope (Figure 5).

We determined that on SB and NP nonwovens with no dust, a biofilm did not develop. Clusters of individual microbial cells (spores of $A$. niger), attached to the fibres, are shown in Figure $5 \mathrm{~d}$,f. For the MB nonwovens in all tested cases, individual microbial cells (Figure 5c), as well as bacterial biofilm sticking fibres and dust together, were observed (Figure $5 \mathrm{a}, \mathrm{b}$ ). For SB and NP nonwovens loaded with both types of dust a biofilm covering single fibers (Figure 5h,e) and one formed in the spaces between them (Figure 5g) was observed. When biofilm is firmly attached to the fibres it lowers porosity of the nonwoven. Individual fibres sticking together following biofilm formation may cause increased breathing resistance when filtering half masks are being used and limit the penetration of dust particles within the structure of the filtering material. On the other hand, cracked fragments of biofilm (Figure $5 \mathrm{~g}$ ) may detach from the nonwoven surface (especially at high air flow velocities), migrate within the filtering material, and penetrate into the organism during breathing, which would constitute a source of secondary inhalation exposure for the worker. 

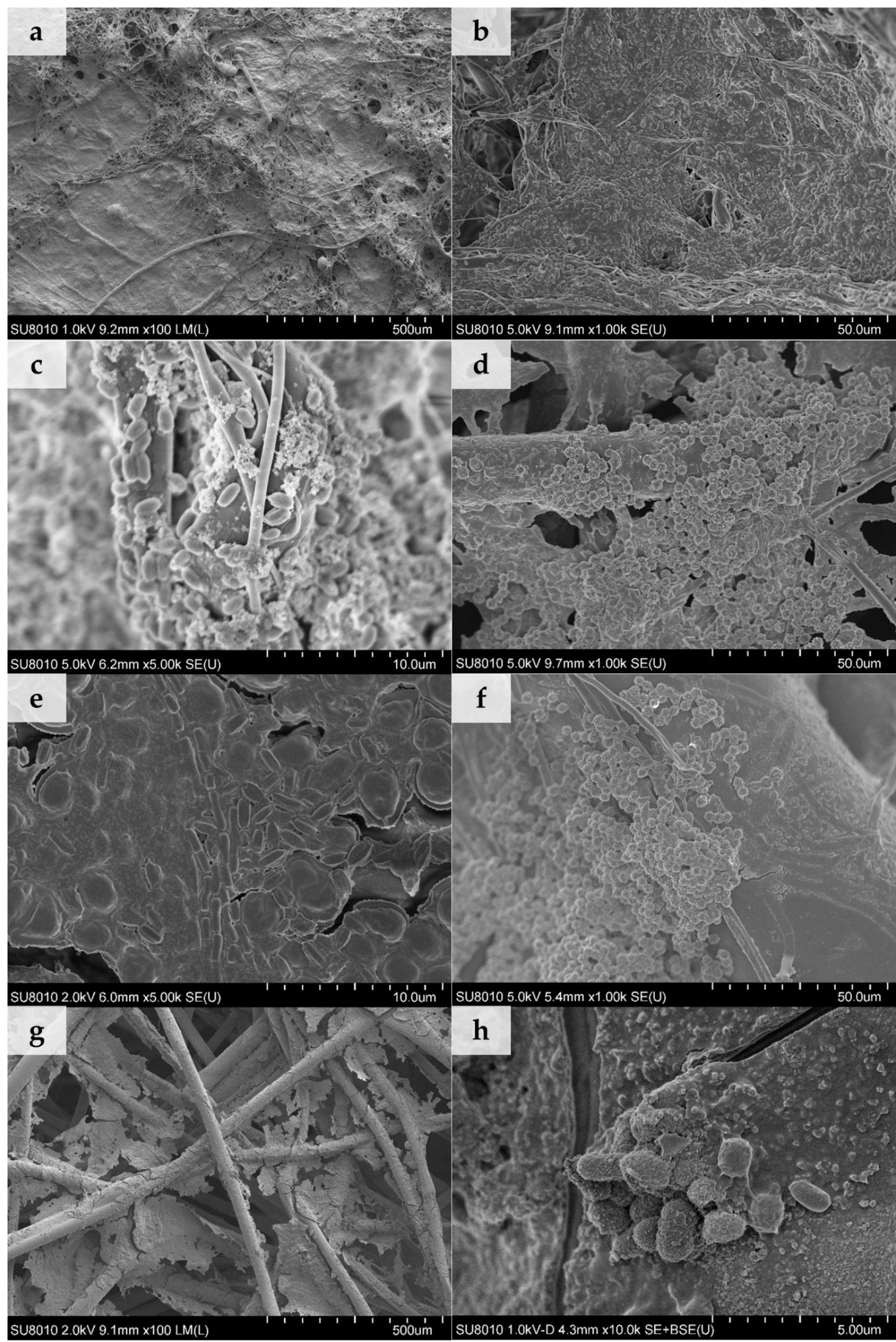

Figure 5. SEM images of biofilms on dust-loaded filtering nonwovens: (a) Control MB nonwoven, (b) MB with dust A, (c) MB with dust B, (d) control SB nonwoven, (e) SB with dust A, (f) control NP nonwoven, (g) NP with dust A, and (h) NP with dust B. 
3.4. The Influence of Microbial Growth on Nanoparticles and Submicron Particles Penetration through Filtering Nonwovens

Figure 6 shows the size distribution of $\mathrm{NaCl}$ aerosol used for penetration testing. Each data point is averaged over five independent measurements.

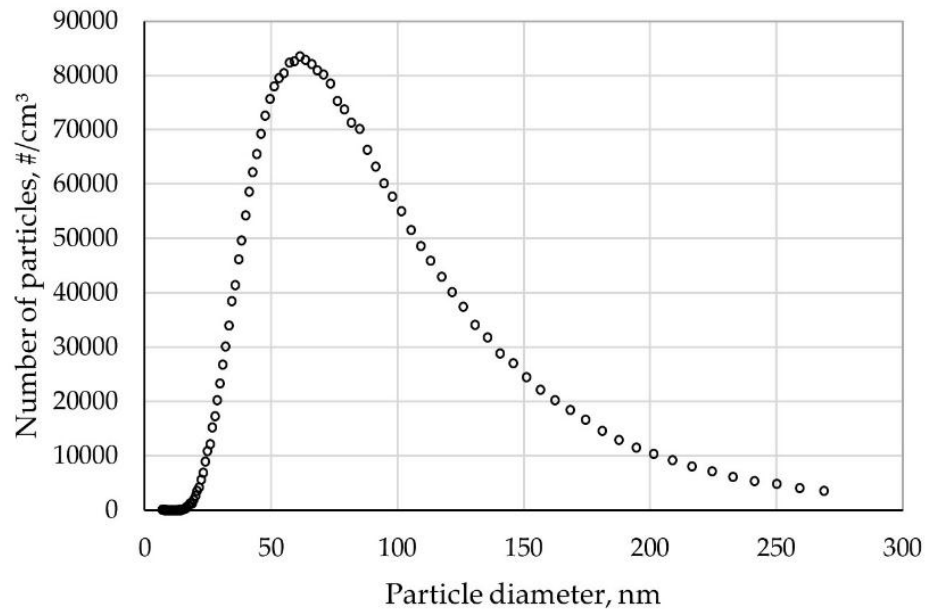

Figure 6. $\mathrm{NaCl}$ particle size distribution.

The diameters of $\mathrm{NaCl}$ particles followed log-normal distribution. The mean geometric diameter for the particle count distribution was $43.7 \mathrm{~nm}$, and the maximum particle number distribution was $8.35 \times 10^{4}$ (Figure 6).

Figure 7 shows penetration of nanoparticles and submicron particles as a function of particle size (7-270 nm) for pristine and inoculated MB nonwovens both with and without dust.
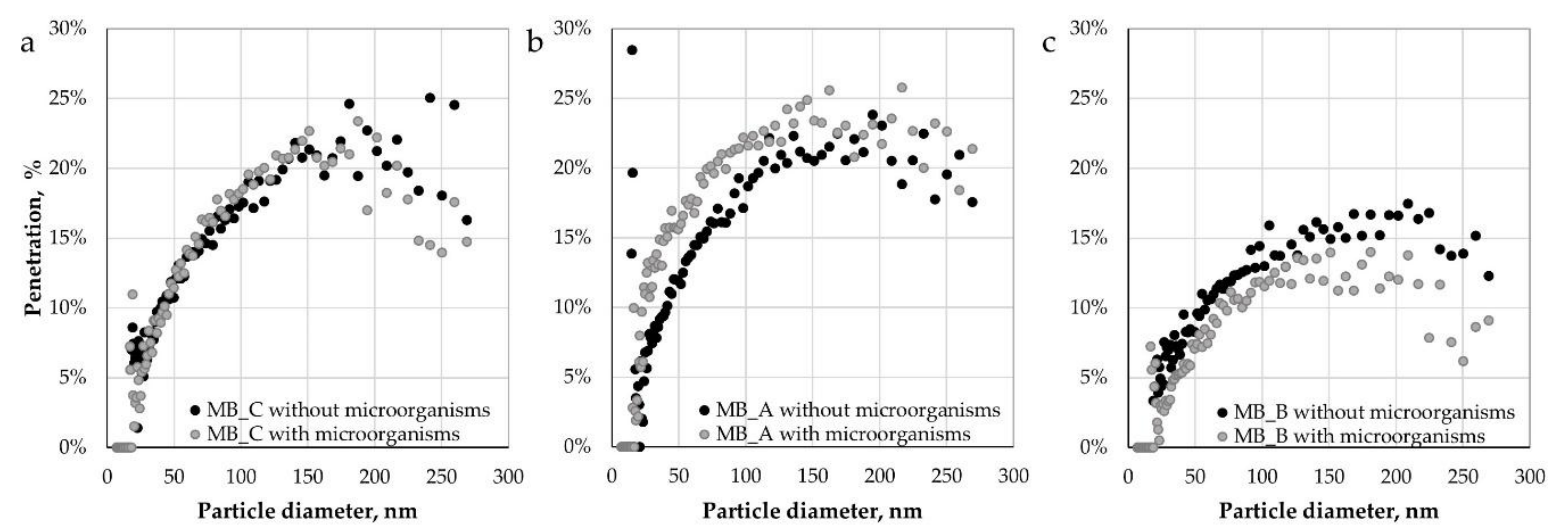

Figure 7. Penetration of nanoparticles and submicron particles through: (a) Control MB nonwovens, (b) MB nonwovens with dust $\mathrm{A}$, and (c) MB nonwovens with dust $\mathrm{B}$.

Similar penetrations (up to approx. 25\%) were observed for control MB nonwovens and MB nonwovens containing dust A (both with and without microorganisms). Significantly lower values of penetration were measured for MB nonwovens with dust B (up to 17.5\%), which might be due to higher dust content that blocks part of the pores of the filtering materials. The obtained penetration values (for control samples) are higher than previously reported in the literature [24], which may be the result of the applied disinfection process in isopropyl alcohol vapours that could lead to a partial discharge of electret material, and hence the weakening of the electrostatic interaction between the fibres and the aerosol particles. This observation is consistent with the previous findings showing diminishing effect of isopropyl alcohol treatment on the electret performance of nonwoven filters [25-27]. For control 
nonwovens, no effect of microbial growth on penetration was observed, while for nonwovens loaded with dust $\mathrm{A}$, the differences occurred only in the particle size range of $20-110 \mathrm{~nm}$. This may indicate the influence of biofilms formation in the presence of dust from composting plant (type A) on the effectiveness of dominant mechanisms in the case of filtration of nanoparticles by such nonwovens, i.e., diffusion mechanism [28-30]. Noticeable decreases in penetration (up to $8.9 \%$ ) in the whole particle size range as a result of microbial growth were noted for the MB nonwoven loaded with dust $\mathrm{B}$. This difference may result from better conditions for biofilm formation, which, by gluing the fibers, reduced the porosity of the nonwoven, and thus increased the efficiency of capturing particles from the stream of flowing air.

\section{Conclusions}

All tested microorganisms, E. coli, C. albicans, and A. niger, were able to survive on dust-loaded polypropylene filtering nonwovens. Some nonwovens were much better suited for survival than others. The microorganisms survived best on the NP nonwoven (survival rate $N=68-5692 \%$ ) and $\mathrm{MB}$ nonwoven $(N=41-1203 \%)$, and had lower survivability on SB nonwoven $(N=57-543 \%)$. Survival was the highest for E. coli $(N=136-150,946 \%)$, lower for $C$. albicans $(N=20-885 \%)$, and lowest for A. niger $(N=25-128 \%)$. The degree of survival of E. coli, C. albicans, and A. niger on the fibres in the presence of dust from the composting or cement plant, depended on the type of microorganism and the amount of dust. Higher survival of E. coli bacteria and A. niger moulds was detected with increasing dust concentrations. The presence of dust did not increase the survival of $C$. albicans yeasts, instead dust from the cement plant significantly reduced the survival of yeasts. Development of microbiological biofilms on tested nonwovens was also confirmed, which may influence filtration efficiency and constitute a source of secondary exposure. Joint influence of dust and microbial growth on penetration of nanoparticles and submicron particles was observed (increase of penetration in case of nonwovens with dust $\mathrm{A}$ and decrease for dust B). Although penetration tests were conducted on a single layer of the FFR and not a complete device, and the electret performance was diminished with the use of isopropyl alcohol, the results indicate that both of those factors should be considered during selection of respirators used for protection against airborne biological agents and establishing times that they can be safely used by workers.

Author Contributions: Conceptualization: K.M., M.O. and B.G.; Data curation: M.O. and A.J.; Investigation: M.O., A.J. and J.S.; Methodology: K.M., M.O. and B.G.; Supervision: K.M. and B.G.; Visualization: M.O. and A.J.; Writing—original draft: K.M., M.O. and A.J.; Writing—review \& editing: K.M., M.O., A.J., J.S. and B.G.

Funding: The publication is based on the results of a research task carried out within the scope of the fourth stage of the National Programme "Improvement of safety and working conditions" partly supported in 2017-2019-within the scope of research and development-by the Ministry of Science and Higher Education/National Centre for Research and Development. The Central Institute for Labour Protection-National Research Institute is the Programme's main coordinator.

Acknowledgments: We would like to express our gratitude to Paweł Kozikowski, PhD (CIOP-PIB) and Dawid Dygas, Bachelor of Engineering (ITFiM) for technical assistance during this research.

Conflicts of Interest: The authors declare no conflict of interest. The funders had no role in the design of the study; in the collection, analyses, or interpretation of data; in the writing of the manuscript, and in the decision to publish the results.

\section{References}

1. Directive 2000/54/EC of The European Parliament and of The Council of 18 September 2000 on the Protection of Workers From Risks Related to Exposure to Biological Agents at Work. Available online: http:/ / www. biosafety.be/PDF/2000_54.pdf (accessed on 27 July 2018).

2. Viegas, S.; Caetano, L.A.; Korkalainen, M.; Faria, T.; Pacífico, C.; Carolino, E.; Quintal Gomes, A.; Viegas, C. Cytotoxic and inflammatory potential of air samples from occupational settings with exposure to organic dust. Toxics 2017, 5, 8. [CrossRef] [PubMed] 
3. Rusca, S.; Charrière, N.; Droz, P.O.; Oppliger, A. Effects of bioaerosol exposure on work-related symptoms among Swiss sawmill workers. Int. Arch. Occup. Environ. Health 2008, 81, 415-421. [CrossRef] [PubMed]

4. Matheson, M.; Benke, G.; Raven, J.; Sim, M.; Kromhout, H.; Vermeulen, R.; Johns, D.P.; Walters, E.H.; Abramson, M.J. Biological dust exposure in the workplace is a risk factor for chronic obstructive pulmonary disease. Thorax 2005, 60, 645-651. [CrossRef] [PubMed]

5. Ahmed, H.O.; Abdullah, A.A. Dust exposure and respiratory symptoms among cement factory workers in the United Arab Emirates. Ind. Health 2012, 50, 214-222. [CrossRef] [PubMed]

6. Pearson, C.; Littlewood, E.; Douglas, P.; Robertson, S.; Gant, T.W.; Hansell, A.L. Exposures and health outcomes in relation to bioaerosol emissions from composting facilities: A systematic review of occupational and community studies. J. Toxicol. Environ. Heal. Part B 2015, 18, 43-69. [CrossRef] [PubMed]

7. Gutarowska, B.; Szulc, J.; Nowak, A.; Otlewska, A.; Okrasa, M.; Jachowicz, A.; Majchrzycka, K. Dust at various workplaces-Microbiological and toxicological threats. Int. J. Environ. Res. Public Health 2018, 15, 877. [CrossRef] [PubMed]

8. Eduard, W.; Heederik, D.; Duchaine, C.; Green, B.J. Bioaerosol exposure assessment in the workplace: The past, present and recent advances. J. Environ. Monit. 2012, 14, 334-339. [CrossRef] [PubMed]

9. Dutkiewicz, J.; Śpiewak, R.; Jabłoński, L.; Szymańska, J. Biological Occupational Risk Factors. Classification, Exposed Occupational Groups, Measurement, Prevention (in Polish); Ad Punctum: Lublin, Poland, 2007.

10. Directive 89/656/EEC of 30 November 1989 on the Minimum Health and Safety Requirements for the Use by Workers of Personal Protective Equipment at the Workplace. Available online: https:/ / eur-lex.europa. eu/legal-content/EN/TXT/PDF/?uri=CELEX:31989L0656\&from=en (accessed on 27 July 2018).

11. Majchrzycka, K.; Okrasa, M.; Skóra, J.; Gutarowska, B. Evaluation of the survivability of microorganisms deposited on filtering respiratory protective devices under varying conditions of humidity. Int. J. Environ. Res. Public Health 2016, 13, 98. [CrossRef] [PubMed]

12. Maus, R.; Goppelsröder, A.; Umhauer, H. Survival of bacterial and mold spores in air filter media. Atmos. Environ. 2001, 35, 105-113. [CrossRef]

13. Jankowska, E.; Reponen, T.; Willeke, K.; Grinshpun, S.A.; Choi, K.J. Collection of fungal spores on air filters and spore reentrainment from filters into air. J. Aerosol. Sci. 2000, 31, 969-978. [CrossRef]

14. Szulc, J.; Otlewska, A.; Okrasa, M.; Majchrzycka, K.; Sulyok, M.; Gutarowska, B. Microbiological contamination at workplaces in a combined heat and power (CHP) station processing plant biomass. Int. J. Environ. Res. Public Health 2017, 14, 99. [CrossRef] [PubMed]

15. Majchrzycka, K.; Okrasa, M.; Szulc, J.; Gutarowska, B. The impact of dust in filter materials of respiratory protective devices on the microorganisms viability. Int. J. Ind. Ergon. 2017, 58, 109-116. [CrossRef]

16. GESTIS: International Occupational Exposure Limit Values for Chemical Agents. Available online: http:/ /limitvalue.ifa.dguv.de/ (accessed on 26 August 2018).

17. Schuster, E.; Dunn-Coleman, N.; Frisvad, J.; van Dijck, P. On the safety of Aspergillus niger-A review. Appl. Microbiol. Biotechnol. 2002, 59, 426-435. [CrossRef] [PubMed]

18. AATCC Test Method 100-2004. Antibacterial Finishes on Textile Materials: Assessment of Antibacterial Finishes on Textile Materials. Technical Manual/2010. 2004. Available online: http://www. manufacturingsolutionscenter.org/aatcc-100-antibacterial-finishes-textile.html (accessed on 30 August 2018).

19. Brown, R.C. Air filtration: An Integrated Approach to the Theory and Applications of Fibrous Filters, 1st ed.; Pergamon Press: Oxford, UK, 1993; ISBN: 00804127429780080412740.

20. Miguel, A.F. Effect of air humidity on the evolution of permeability and performance of a fibrous filter during loading with hygroscopic and non-hygroscopic particles. J. Aerosol Sci. 2003, 34, 783-799. [CrossRef]

21. Russell, A.D. Similarities and differences in the responses of microorganisms to biocides. J. Antimicrob. Chemother. 2003, 52, 750-763. [CrossRef] [PubMed]

22. Gutarowska, B.; Skóra, J.; Zduniak, K.; Rembisz, D. Analysis of the sensitivity of microorganisms contaminating museums and archives to silver nanoparticles. Int. Biodeterior. Biodegradation 2012, 68, 7-17. [CrossRef]

23. Gutarowska, B.; Skóra, J.; Nowak, E.; Łysiak, I.; Wdówka, M. Antimicrobial activity and filtration effectiveness of nonwovens with Sanitized for respiratory protective equipment. Fibres Text. East. Eur. 2014, 22, 120-125. 
24. Brochocka, A.; Makowski, K.; Majchrzycka, K.; Grzybowski, P. Efficiency of filtering materials used in respiratory protective devices against nanoparticles. Int. J. Occup. Saf. Ergon. 2013, 19, 285-295. [CrossRef] [PubMed]

25. Viscusi, D.J.; Bergman, M.S.; Eimer, B.C.; Shaffer, R.E. Evaluation of five decontamination methods for filtering facepiece respirators. Ann. Occup. Hyg. 2009, 53, 815-827. [CrossRef] [PubMed]

26. Viscusi, D.; King, W.P.; Shaffer, R.E. Effect of decontamination on the filtration efficiency of two filtering facepiece respirator models. J. Int. Soc. Respir. Prot. 2007, 24, 93-107.

27. Zhou, Y.; Cheng, Y.S. Evaluation of N95 filtering facepiece respirators challenged with engineered nanoparticles. Aerosol Air Qual. Res. 2016, 16, 212-220. [CrossRef]

28. Bałazy, A.; Podgórski, A.; Gradoń, L. Filtration of nanosized aerosol particles in fibrous filters. I-Experimental results. J. Aerosol Sci. 2004, 35, 967-980. [CrossRef]

29. Wang, C.; Otani, Y. Removal of nanoparticles from gas streams by fibrous filters: A review. Ind. Eng. Chem. Res. 2013, 52, 5-17. [CrossRef]

30. Wang, J.; Chen, D.R.; Pui, D.Y.H. Modeling of filtration efficiency of nanoparticles in standard filter media. J. Nanoparticle Res. 2007, 9, 109-115. [CrossRef]

(C) 2018 by the authors. Licensee MDPI, Basel, Switzerland. This article is an open access article distributed under the terms and conditions of the Creative Commons Attribution (CC BY) license (http:/ / creativecommons.org/licenses/by/4.0/). 